\title{
A criação do imaginário em narrativas de estudantes brasileiros: perspectivas a partir das Olimpíadas de Língua Portuguesa
}

\section{Gleiser Mateus Ferreira Valério ${ }^{1}$}

\begin{abstract}
Resumo: Em O fictício e o imaginário, Iser parte da distinção entre realidade e ficcional, abrindo espaço para um terceiro elemento - o imaginário. Para tal, converte-o em experiência do que o autor denomina em um "como se". Por meio de escolhas, o indivíduo seleciona as "chaves" de leitura que utilizará para perceber e receber o texto literário e, deste modo, conceber suas próprias narrativas. Pelo imaginário, o texto se torna algo possível e desenvolve o processo representativo. No presente artigo, a categoria lugar será uma destas "chaves", partindo das Olimpíadas de Língua Portuguesa (OLP). Durante a realização do concurso, os estudantes participam de um processo pedagógico que se utiliza da Literatura como forma do jovem perceber o "ser" e o "estar no mundo", partindo de seu lugar (espacial e de fala) no qual se situa para criar narrativas pessoais. Para tal, a OLP tem como tema "O lugar onde vivo", sendo assim, um elemento de seleção é instaurado para o processo criativo que é o espaço vivenciado e experimentado pelo educando. Nesta análise, será utilizado, como base, o poema "As Marias do meu lugar", selecionado e publicizado nas coletâneas de poemas do projeto, ao lado de autores como Carlos Drummond Andrade e Fernando Pessoa, dando um caráter de escrita autoral à produção juvenil. O objetivo não será apenas questionar o processo criativo, mas também trazer o elemento local como potencializador do imaginário ao descrever um espaço fora dos grandes centros ou de capitais - a individualidade de uma pequena cidade do interior do Nordeste brasileiro, seu povo e suas particularidades.
\end{abstract}

Palavras-chave: Literatura. Leitura. Imaginário. Escrita. Lugar/Localismo.

\section{The creation of the imaginary in Brazilian students narratives: perspectives from the Olimpíadas de Língua Portuguesa}

\begin{abstract}
In The fictive and the imaginary, Iser starts from the distinction between reality and fiction, opening space for a third element - the imaginary. To do that, it turns into an experience of what the author calls a "as if." Through choices, the individual selects the "keys" of reading that he will use to perceive and receive the literary text and, thus, to conceive his own narratives. By the imaginary, the text becomes something possible and develops the representative process. In this article, the place category will be one of these "keys", starting from the Olimpíadas de Língua Portuguesa (OLP). During the contest, students participate in a pedagogical process that uses Literature as a way for young people to perceive "being" and "being in the world", starting from their place (spatial and speech) in which they take place themselves to create personal narratives. To this end, the OLP has as its theme "The place where I live", so that a selection element is established for the creative process that is the space lived and experienced by the student. In this analysis, the poem "As Marias do meu lugar", selected and publicized in the collection of poems of the project, will be used as a base, along with authors such as Carlos Drummond Andrade and Fernando Pessoa, giving a writing character to youth production. The objective will not only be to question the creative process, but also to bring the local element as a potentiator of the imaginary when describing a space outside the great centers or capitals - the individuality of a small city in the interior of the Brazilian Northeast, its people and its particularities.
\end{abstract}

Keywords: Literature. Reading. Imaginary. Writing. Place/Localism.

\footnotetext{
${ }^{1}$ Doutorando e mestre em Literatura e Práticas Sociais na Universidade de Brasília. Graduado em Letras - língua portuguesa e respectivas literaturas pela mesma universidade. Atualmente atua como professor da educação básica na Secretaria de Estado de Educação do Distrito Federal e desenvolve pesquisa nas áreas de: leitura, escrita, ensino e autoria estudantil. E-mail: gleisermateus@hotmail.com.
} 


\section{INTRODUÇÃO}

Na composição do texto, o autor se utiliza do imaginário para criar novos mundos, experimentar novas realidades ou mesmo se aproximar e questionar a sua própria. De outro lado, a partir da leitura, o indivíduo estabelece conexões, relaciona, dialoga e propõe comparações. Para poder decifrar a escrita, chaves são postas e escolhidas para que se possa interpretar e fazer com que os significados assumam perspectivas. Tanto leitor, quanto autor são as peças fundamentais desse jogo que é a própria narrativa, seres intercambiáveis e codependentes no processo de criação do literário e que se mesclam ao ponto de se relacionar e se imbricar de tal maneira que façam com que esse contato gere novas possibilidades de textos.

A partir dessa ligação que o presente artigo parte - do nexo entre o imaginário do autor, o processo de leitura e a conexão com o leitor ao ponto de despertar novas criações literárias com caráter intertextual. Para tal, partimos de um estudante de escola pública brasileira nas Olimpíadas de Língua Portuguesa $(\mathrm{OLP})^{2}$ e na narrativa "As Marias do meu lugar" criada a partir do concurso literário. Sendo assim, amparamos no conceito proposto por Iser do de imaginário que está para além do real ou do fictício, mas um elemento fundamental para se pensar o fazer literário.

Num primeiro momento, será questionado o processo criativo e como é organizado para que o autor seja capaz de compor realidades que estão presentes no âmbito ficcional. $\mathrm{O}$ jogo proposto pela narrativa será explicitado e colocado em evidência para que se compreenda $\mathrm{o}$ ato criativo e como a fantasia e o imaginário são trazidos à tona para se pensar o literário. Com objetivo de estabelecer uma relação mais direta com a escrita estudantil, será pensado a experimentação do objeto artístico e como ele é capaz de despertar novas possibilidades de composição, novos textos e visões originais a partir de um elemento já existente, num movimento de intertextualidades e dialogismo que é próprio da Literatura. Sendo assim, o

\footnotetext{
${ }^{2}$ Projeto desenvolvido pelo Ministério da Educação, em parceria com órgãos como CENPEC, canal Futura e Itaú Social, com a finalidade de promover atividades de escrita em âmbito escolar. Iniciado em 2002 como proposta piloto chamada Escrevendo o Futuro, assumiu o caráter de concurso em 2008 com a realização da primeira Olimpíada de Língua Portuguesa, já no formato que permanece até hoje. Organiza-se em oficinas baseadas na teoria de sequência didática, nas quais há propostas para atividades de leitura (Coletânea de textos literários) e escrita. As narrativas são compostas, inicialmente, na escola, na qual apenas um texto é selecionado de acordo com o gênero do ano escolar (a saber: $5^{\circ}$ e $6^{\circ}$ anos - poema, $7^{\circ}$ e $8^{\circ}$ anos - memórias, $9^{\circ}$ e $1^{\circ}$ ano do ensino médio - crônica, $2^{\circ}$ e $3^{\circ}$ anos do ensino médio - artigo de opinião). Posteriormente, há seleção nos âmbitos estadual, regional e nacional na qual há a publicação de coletânea com os semifinalistas de todo o país e premiação dos textos que chegaram à final. Todas as edições mantém a mesma temática - O lugar onde vivo - com a finalidade de estimular o estudante a conhecer melhor seu espaço de vivência e a comunidade da qual faz parte e compõe sua identidade enquanto indivíduo que é parte de um coletivo.
} 


\section{ITIFRAR REFLECTIONIS}

Revista Eletrônica de Graduação e Pós-Graduação em Educaçāo

imaginário será considerado a partir do contexto no qual é transformado em elemento escrito, bem como sua capacidade de despertar novas visões de realidade a partir dos processos de leitura.

Munido da discussão a respeito do processo criativo, o poema As Marias do meu lugar, texto selecionado pela OLP e presente na coletânea literária de seu gênero específico poesia, servirá como ponto central para a concretização do imaginário como elemento ficcional. Com o intuito de se pensar um foco para a análise, o conceito de lugar, em contato com o de local, enquanto elemento de indagação sob o prisma da decolonialidade, será chave para se entender a representação do espaço a partir do específico, do periférico em oposição ao central, do lócus individual, contrapondo ao coletivo, normalmente visto como padrão.

\section{EXPERIÊNCIA, IMAGINÁRIO, FICCIONAL E LEITURA}

A obra Literária, assim como a arte em geral, constrói-se por meio da interação do autor em sua visão da realidade, promovida pela experimentação dos eventos cotidianos que o cerca. São intenções conscientes organizadas por meio de emoções advindas do próprio viver (DEWEY, 2010, p. 107). Podemos assim dizer que o escritor concebe um universo imaginário composto por dados que sua experiência diária oferece e a retrata em um ambiente ficcional perpassado por suas concepções de como a vivenciou.

Ao pensar deste modo, observamos que a escrita se engendra por meio de uma construção de memória na qual o autor faz e refaz, de maneira estética, ao compor uma obra. É pela experiência que o fazer artístico toma forma e adquire substância para gerar o resultado final que é o texto enquanto arte. Nesta relação entre o observado e o experimentado, Dewey aponta um elemento fundamental para a produção artística, a necessidade de recriação. O limite para a arte não está apenas na recepção, mas na interação com esta para possibilidade de se elaborar novas obras que sejam significativas, algo que para o autor é indissociável, tal como define: a experiência estética - em seu sentido estrito - é vista como inerentemente ligada à experiência de criar (Idem, p. 129).

A experimentação e recriação, a partir da leitura, entra o diálogo com o conceito postulado por Iser de imaginário. $\mathrm{O}$ autor parte da quebra da dicotomia que sustenta muitas discussões sobre a Literatura - o real e o ficcional, inserindo um elemento que entremeia ambos e questiona o ato criativo - o imaginário. $\mathrm{O}$ texto então pode ser questionado como algo 


\section{ITHerapuns REFLETIONIS}

Revista Eletrônica de Graduação e Pós-Graduação em Educaçāo

transgressor dentro dos limites de sua elaboração. Mais que apenas uma visão do mundo, ou um foco na perspectiva social que esta construção traz, ele possui um cunho sentimental, emocional, onírico e fantasioso.

Não apenas um processo mimético de construção do mundo, mas uma repetição da realidade transformada em signo, um ato de fingir que funciona como transgressão de limites, como afirma Iser: O imaginário não se transforma em real, mas adquire experiência e auxilia a agir no mundo (ISER, 2013, p. 33). Não se trata de copiar, mas de reformular o mundo a partir da percepção, experimentar os acontecimentos por meio do texto e buscar as relações que são estabelecidas com a finalidade de se construir o ficcional. De tal maneira, o mundo é decomposto baseado na seleção feita pelo indivíduo, em consonância com a intencionalidade e a combinação, o que compõe o ato de fingir segundo Iser.

No jogo proposto pela obra, um contrato é estabelecido entre autor e leitor para promover a criação do discurso que Iser conceitua como encenado. $\mathrm{O}$ teórico denomina o texto literário como uma forma determinada de acesso ao mundo, não o imitando, mas o decompondo (o que denomina como seleção) de elemento socioculturais e mesmo literários que auxiliam na composição, como descreve: o texto ficcional contém fragmentos identificáveis da realidade e das leituras prévias (idem, p.43). Nesta perspectiva parte a proposta presente no artigo, o contato entre o que é lido e experimentado e como este promove a nova criação. No ambiente escolar, o estudante entra em diálogo com a Literatura, ativa seu imaginário a partir do cotidiano e de seu referencial de mundo, num processo polifônico e intertextual que promove a produção de obras com originalidade, efeito que tem a OLP como provocadora. Iser questiona este câmbio intertextual que é fundamental para se pensar a escrita:

$\mathrm{O}$ ato de seleção também invade outros textos, com isso engendrando a intertextualidade [...] Como os dois tipos de contextos se atualizam, surge uma coexistência de discursos diferentes, que desenvolvem seus contextos como um jogo de mútuo aparecimento e desaparecimento. Daí resulta uma instabilidade semântica que se avoluma porque os discursos reunidos constituem também contextos uns para outros, de modo a se inserirem em uma relação de tema e horizonte, e movendo-se incessantemente entre si [...] Quanto mais um texto acumula outros textos em si, tanto mais intensamente se expressa a duplicação produzida pelo ato de seleção (ISER, 2013, p. 300).

A seleção envolve esta ação combinatória entre textos que se encontram, relacionam e inter-relacionam para a possibilidade de resultar em respostas capazes de formular novos mundos vividos e experimentados e autorais. Os jovens de escolas públicas, em contato com autores já renomados nacionalmente, por meio do ensino de literatura promovido pela 


\title{
IrIfRARIus REFLECTIONIS
}

Revista Eletrônica de Graduação e Pós-Graduação em Educaçāo

OLP, são capazes de repensar sua realidade a partir do que leem. A recepção deixa de ser um elemento apenas contemplativo para se inserir numa discussão que envolve o imaginário e seu uso para novas produções. De tal maneira, as obras se tornam contextos para novas obras, como observado em Iser sobre a acumulação de um texto em outro, em ser parte constitutiva deste e expressar o processo seletivo, relacionado à intencionalidade e a combinação, no que descreve num "como se" que é central para a discussão sobre o imaginário, tal como denomina: cada palavra se torna dialógica, cada campo semântico é duplicado por um outro (idem, p.300).

Neste processo é que as diversas leituras que se encontram, estabelecem conexão e produzem uma nova obra capaz relacionar toda uma cadeia intrínseca de relações. Trata-se de um encadeamento possível segundo uma perspectiva dialógica da arte, partindo do pressuposto de que a participação do leitor não se dá de maneira puramente contemplativa ou passiva no ato da leitura, ao contrário, espera-se que, ao preencher, com suas perspectivas, a interpretação da obra, promova-se uma resposta e uma interação, sendo a Literatura dialógica, intertextual e polifônica, tal como afirma Bakhtin:

\begin{abstract}
A obra, como a réplica do diálogo, está disposta para a resposta do outro (dos outros), para a sua ativa compreensão responsiva, que pode assumir diferentes formas: influência educativa sobre os leitores, sobre suas convicções, respostas críticas, influência sobre os seguidores e continuadores; ela determina as posições responsivas dos outros nas complexas condições de comunicação discursiva de um dado campo da cultura. A obra é um elo na cadeia da comunicação discursiva; como a réplica do diálogo, está vinculada com outras obras - enunciados: com aquelas às quais ela responde, e com aquelas que lhe respondem; ao mesmo tempo, à semelhança da réplica do diálogo, ela está separada daqueles limites absolutos da alternância dos sujeitos do discurso (BAKHTIN, 2003, p. 279).
\end{abstract}

No encontro entre estas várias vozes e textos que se entremeiam, cruzam e dialogam, percebemos uma das finalidades principais no que tange à autoria de novas narrativas que é a busca de maneiras de se apresentar o mundo por meio do texto, e nele refletir sobre sua realidade. Cada autor buscará uma forma diferente de produzir seus livros em meio ao momento vivenciado.

Por meio da leitura, os elementos do dia a dia se tornam escrita, memória, como diria Garcez: em um movimento constante de recriação e reinterpretação de informações, conceitos e significados (GARCEZ, 2010, p. 50). Tal visão dialoga com o que preceitua Petit: por meio do livro que o estudante experimente a fuga de seu exílio interior, constrói seu dia a dia através do fio condutor de sua própria história e se apropria do texto literário para atravessar mesmo situações de dificuldade em que vive (PETIT, 2009, p. 266). 


\section{ITHeparius REFLETIONIS}

Revista Eletrônica de Graduação e Pós-Graduação em Educaçāo

De maneira geral, é apenas na escola que a criança de periferia possui contato com esta realidade tão "diferente" da sua. No ambiente da sala de aula, que é parte de seu lugar, o professor pode se utilizar dos recursos e teorias literárias para auxiliar o aluno a se compreender como fundamental para a realidade em que vive. Os livros abrem as portas para o conhecimento do espaço do indivíduo e as experiências ali vividas, fazendo com que o jovem se aproprie da linguagem literária e ocupe os espaços, em suas múltiplas possibilidades, dos quais é componente, buscando uma maneira de "pertencer ao mundo" (PETIT, 2008, p. 84).

O leitor, por meio do imaginário, do "como se" que é importante para a composição, age de maneira ativa ao ser capaz de sair do que é proposto pelo próprio texto. Sendo assim, voltamos para Petit ao declarar que: o leitor não consome passivamente um texto, ele se apropria dele, o interpreta, deturpa seu sentido, desliza sua fantasia, seu desejo, suas angústias entre as linhas e as mescla com a do autor. É aí, em toda essa atividade fantasmática, neste trabalho psíquico, que o leitor se constrói (PETIT, 2013, p.27). Nesta postura responsiva do leitor que surge a possibilidade de reformular suas experiências e as conduzir a uma nova possibilidade, os acontecimentos se mesclam e promovem algo original a partir da relação dialógica e intertextual provocada pelo texto literário. Ao assumir sua narrativa, mesmo que diretamente mergulhada num conjunto de discursos que o antecede e o completa, o leitor adentra seu território íntimo, num processo, ao mesmo tempo polifônico e individual, pelo fato de estar em contato constante com o que leu e o que vivencia, fazendo com que seja capaz de criar e resistir mediante sua capacidade imaginativa. Podemos estabelecer uma interlocução com Petit que denomina: E em ressonância com as palavras do autor, nos rugem palavras, palavras inéditas. É um pouco como se nos tornássemos o narrador daquilo que vivemos (idem, p.110).

No contexto da OLP, a chave para leitura das narrativas compostas pelos estudantes parte do conceito de lugar, enquanto elemento de experimentação, de contato com o mundo que o cerca e de onde o indivíduo se situa para se expressar, em diálogo com o que foi proposto sobre o processo criativo, o imaginário e o intertextual. Com a finalidade de se compreender este espaço, será necessário intercambiar a discussão sobre lugar com o conceito de local, numa perspectiva que parte da teoria decolonial, para se retirar o foco desta visão universalizante do todo a partir dos centros e direcionando para o periférico, o que se dará pela análise do poema As Marias de meu lugar de um jovem estudante da região Nordeste brasileira. Se tanto foi dito sobre a seleção, intenção e combinação (o como se), teremos aqui uma concretização desta proposta conceitual pela interpretação do produto concretizado, o que Dewey descreve pela 
experiência que gera novas experiências. Pelas leituras promovidas no ambiente escolar, os alunos se aproximam dos conflitos sociais dos quais são parte integrante, dos temas da sociedade que os interessam e são parte de si e de seu "estar no mundo", seu referencial cultural e das relações que o constrói (dentre elas a familiar e de comunidade), o que, para Petit, leva a outras formas de sociabilidade e de solidariedade; e pode conduzi-los a outras maneiras de morar e de perceber o bairro, a cidade, o país em que vivem (PETIT, 2013, p. 114).

\section{O LUGAR E O LOCAL NA CONSTRUÇÃO DO IMAGINÁRIO NA NARRATIVA ESTUDANTIL}

\section{As Marias do meu lugar} I

Minha terra é pequenina

Fica aqui no Ceará

No Vale do Jaguaribe

Alto Santo aqui está

No Comando das Marias

Que progride esse lugar

II

Tem Maria sertaneja

Valente feito um trovão

Daquela que desde cedo

Faz o cultivo do chão

E a Maria tratorista

Que ajuda na plantação

III

Tem Maria lá na câmara

Que é a vereadora

Tem Maria que cedinho

Limpa a rua com a vassoura
Tem aquela que ensina

A Maria professora

IV

A Maria forrozeira

Rodeia feito pião

Tem a Maria louceira

Transforma o barro com a mão

E a Maria morena

Com corpo de violão

V

Maria que no mercado

Vende o quente e o frio

E a Maria lavadeira

Faz espuma lá no rio

E a Maria açougueira

Com a faca faz desafio

VI

Maria no hospital

A Maria enfermeira
Lá na fábrica de tecidos

A Maria costureira

$E$ aqui na minha casa

A Maria verdadeira

VII

Lá no altar da igreja

Maria diz o amém

Implora ao padroeiro

Para todos viver bem

A mãe do Menino Deus

Que é Maria também

VIII

Ah! Se em todo lugar tivesse

Assim tantas alegrias

E que fosse como meu

Nessa paz do dia-a-dia

Que faz o calor do sol

Dar força a essas Marias

(Coletânea de Poemas -

OLP) 


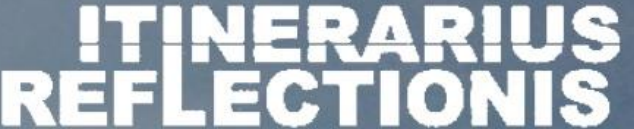

Revista Eletrônica de Graduação e Pós-Graduação em Educaçāo

As relações sociais de um indivíduo se constroem tendo como base o lugar de vivência e é daí que sua fala se estrutura, "suas experiências se constroem, não universais, mas particulares, singulares e próprias de cada pessoa" (MASSEY, 1994, p. 184). Neste elemento espacial que as inter-relações se constituem, bem como, há a conexão com o exterior que o cerca. É de onde se encontra que qualquer ser humano inicia o processo de experimentação citado anteriormente. A família, a casa, os amigos, a escola, dentre outras partes fundamentais da comunidade são a base de formação da identidade. Neste ambiente é que se pode expressar sua individualidade, construir suas memórias, perceber como parte de um todo estruturante. É, como diria Callai (2004, p.02) “o Lugar onde se vive deve ser conhecido e reconhecido pelos que ali vivem, por conhecer o espaço, para saber nele se movimentar, para nele trabalhar e produzir, significa reproduzir-se também a si próprio, como sujeito".

Neste lugar, o estudante deve se sentir parte e construir noções de temporalidade, em que se forme questões singulares e individuais fundamentais para a sua identidade. As possibilidades vivenciadas são geradas por meio da ação como ator/autor da própria vida que se estabelece a partir desta espacialidade da qual habita. A história de vida de qualquer um se baseia na concatenação de elementos elencados segundo seu referencial de lugar no qual não somente se vive, mas estabelece uma complexa cadeia de relações que: ao ler o espaço, a criança estará lendo a sua própria história, representada concretamente pelo que resulta das forças sociais e, particularmente, pela vivência de seus antepassados e dos grupos com os quais convive atualmente (CALLAI, 2005, p. 237).

Ao questionar o seu lugar, o estudante se situa numa discussão ainda maior. Neste espaço ele não só participa de sua vida, mas também compartilha as experiências de toda a comunidade na qual é inserido. Tal como questiona Mignolo (2003), o local pode ser visto não apenas em seu âmbito geográfico, mas em seu sentido histórico. As experiências partem de elementos da sensibilidade das pessoas, manifestações que podem ter, na escola, um ambiente de trocas e no qual o educando se compreende como parte de um todo da qual é elemento integrante. Pela experiência da leitura: um sentido de territorialidade se assume ao incluir elementos como a língua, os odores, a paisagem, o clima e todos esses signos básicos que ligam o corpo a um ou a diversos lugares (MIGNOLO, 2003, p. 264).

É nesta premissa que o conceito de lugar entra em diálogo com o de local proposto por Mignolo enquanto elemento de particularização do indivíduo em oposição ao conceito de universal. No caso da OLP, usaremos o poema As Marias do meu lugar como ponto 


\section{IrIfRARIus REFLECTIONIS}

Revista Eletrônica de Graduação e Pós-Graduação em Educaçāo

fundamental para se questionar a escolha do lugar como chave de interpretação do texto. Os saberes advindos das obras de autores da literatura em língua portuguesa (a saber: Casimiro de Abreu, Fernando Pessoa, Patativa do Assaré, Machado de Assis, Mário Quintana, entre outros) entram em contato com os conhecimentos próprios do estudante e de sua leitura de si e do mundo. Por meio desta relação, os elementos anteriormente questionados sobre o imaginário e o processo criativo promovem a elaboração de narrativas com caráter autoral dos alunos, valorizadas ao ponto de ser inseridas na coletânea oficial de textos literários ao lado dos atores que serviram de inspiração e base para o despertar do imagético e, desta maneira, estabelecer conexão entre o espaço experimentado pelo que é lido e o real.

Pela leitura do mundo, o aluno experimenta a palavra escrita. Das experiências que os anos, em seu local do qual é parte constitutiva, oferecem. Assim se configura o processo de aprendizagem do texto literário em sua integridade. Mais que apenas ler, o estudante contextualiza a obra por meio seus atos íntimos e pessoais, como diria Paulo Freire: a leitura da palavra não é apenas precedida pela leitura de mundo, mas por uma certa forma de escrevê-lo, quer dizer, de transformá-lo através de nossa prática consciente FREIRE, 2011, p. 30). Em sua história particular, simples do cotidiano das ruas que a relação entre autores conhecidos e o estudante entra em confluência de suas realidades (mesmo que de uma obra ficcional), num “espaço condensador de espaços e espaços" (WALTY, 1985, p. 103).

Na poesia do aluno de Alto Santo, Ceará, encontramos, já nos versos iniciais, tal perspectiva a respeito do lugar: Minha terra é pequenina/ Alto Santo aqui está/ No comando das Marias/ Que progride esse lugar (MEC, 2014, p.16). Numa linguagem simples, o jovem se utiliza do referencial advindo dos poetas lidos, em especial o cordelista nordestino Patativa do Assaré e o poeta Gonçalves Dias com seu O canto do Exílio, para situar o eu-lírico no elemento local particular que é a cidade de Alto Santo. Num microuniverso, a cidade é metaforizada a partir de algo que é ainda mais particular de sua constituição - as Marias. Não temos o foco nas grandes temáticas da lírica ocidental, mas, sim, voltamos para um dos nomes mais comuns brasileiros e, acima de tudo, em um olhar que contraria o patriarcalismo, que ainda domina nossa sociedade, ao ter o feminino como força motriz que organiza e progride o lugar de onde se fala.

Desta maneira, o estudante estabelece contato de sua leitura na escola com o experimentado no cotidiano, ocupa seu lugar por meio de palavras que expõem possibilidades para a investigação de sua própria narrativa. Candido (2015) questiona a obra como "um 


\section{HTiparys REFLETIONIS}

Revista Eletrônica de Graduação e Pós-Graduação em Educaçāo

mundo", por meio do qual o autor reordena, transforma, desfigura, põe de lado e passa a gerar outros. Nesta perspectiva que partem as possíveis hipóteses de pesquisa, ao reconhecer e interpretar estes espaços não só como forma de ser parte do mundo, mas também de se criar o mundo. Não uma ideia de país ou de todo voltada para a perspectiva global ou universal como prescrita pelas bases teóricas eurocêntricas colonizadoras, mas voltamos o olhar para o colonizado, para o periférico das terras brasileiras que é, ainda na realidade atual, a região Nordeste e em uma pequena cidade do interior do Ceará.

As Marias, que simbolizam a construção do lugar, promovem o desenvolvimento da cidade por meio de vários vieses: numa perspectiva cultural temos a Maria forrozeira, num âmbito econômico as mulheres tratoristas, professoras, louceiras, lavadeiras, enfermeiras, costureiras, açougueiras, numa posição política, a vereadora, ainda existem as rezadeiras e a própria entidade máxima do cristianismo que é a Maria mãe e divina. Neste ponto de vista, o local assume um aspecto decolonial descolando dos conceitos ditos universalizantes, mesmo que mantendo o processo dialógico com o referencial do qual parte na literatura, aproximando do que preceitua Mignolo: Ademais a gnose/pensamento liminar pode servir como mediador entre as duas questões inter-relacionadas que aqui estou introduzindo: saberes subjugados e o dilema universal/particular (MIGNOLO, 2003, p. 44). O pensamento liminar de Mignolo traz à tona as questões locais em foco e promove a apropriação do espaço por meio de seus elementos particulares, basilar para o pensamento decolonial. Nas afirmações do autor:

\footnotetext{
Essas narrativas não são contrapontos da história mundial ou universal (seja ela sagrada como a história cristã ou secular como a de Hegel), mas uma ruptura radical com tais projeto globais. Não são (ou, pelo menos, não apenas) nem narrativas revisionistas, nem narrativas que pretendem contar uma história diferente, mas, sim, narrativas acionadas pela busca de uma lógica diferente (MIGNOLO, 2003, p.47).
}

Essa discussão atinge seu limiar no encerramento do poema: Ah! Se em todo lugar tivesse/ Assim tantas alegrias/ E que fosse como meu/ Nessa paz do dia a dia/ Que faz o calor do sol/ Dar forças a essas Marias (MEC, 2014, p.16). Temos a percepção desta lógica diferente pela construção da cidade a partir dos indivíduos que a constroem. Alegria, paz, cotidiano e sol, que é o símbolo maior quando se fala do Nordeste brasileiro, são a força que conduzem as Marias em sua dura jornada na construção do lugar, dando um novo vigor e uma nova roupagem às vidas "severinas", parafraseando João Cabral de Melo Neto. 


\section{IrIfRARIus REFLECTIONIS}

Revista Eletrônica de Graduação e Pós-Graduação em Educaçāo

\section{CONSIDERAÇÕES FINAIS}

Pela leitura, o literário é experimentado e se torna fundamental para que novas criações textuais sejam possíveis. O leitor adentra o universo fictício e se apropria de suas características e particularidades, seleciona e combina sua própria concepção de real com a do texto, num processo dialógico e intertextual que desenvolve a construção do imaginário, como proposto por Iser e Bakhtin. Neste jogo promovido pelo texto, o lugar, este espaço que não é somente físico, mas de vivência, trocas e de construção de si, bem como do outro, torna-se central para a possibilidade de elaboração de narrativas que a OLP procura gerar. Partimos deste "lugar onde vivo" (tema do concurso) para a produção de histórias e poemas autorais de estudantes que, talvez somente neste momento, possam expor suas concepções do mundo, da representação do seu lugar que é palpável enquanto território, simbólico enquanto referente, coletivo enquanto vivenciado pela comunidade e legitimado pela fala autorizada na publicização da coletânea.

É desta forma que estabelecemos relação com o conceito decolonial de localismo/local. As narrativas oferecem o olhar diferente que sai do horizonte colonizador eurocêntrico, de uma análise que, por séculos, foi e é a base para a interpretação da Literatura ocidental. Não procuramos aqui estabelecer um novo conceito fora da tradição, e, sim, um novo foco para questionar temáticas e saberes fora do centro, voltando-se para o periférico e o marginalizado, nesse caso, representado na pequena cidade de Alto Santo e, ainda mais particular, no elemento humano situado no signo das Marias.

\section{REFERÊNCIAS}

BAKHTIN, M. Estética da criação verbal. Trad. Paulo Bezerra. 4 ed. São Paulo: Martins Fontes, 2003.

CALLAI, H. C. O estudo do Lugar como possibilidade de construção de identidade e pertencimento. VIII Congresso luso-afro-brasileiro de ciências sociais. Coimbra, 2004.

\section{Aprender a ler o mundo: a geografia nos anos iniciais do Ensino} Fundamental. Cad. Caedes, Campinas, vol.25, n66, p. 227-247, mai/ago. 2005.

CANDIDO, A. De cortiço a cortiço, In: $O$ discurso e a cidade. $5^{\text {a }}$ ed. Rio de Janeiro: Ouro sobre azul, 2015.

DEWEY, J. A arte como experiência. São Paulo: Martins Fontes, 2010. 


\section{IrIfRARIus REFLCTIONIS}

Revista Eletrônica de Graduação e Pós-Graduação em Educaçāo

FREIRE, P. A importância do ato de ler: em três artigos que se completam. $51^{a}$ ed. São Paulo: Cortez, 2011.

GARCEZ, L. H. C. A escrita e o outro: os modos de participação na construção do texto. Brasília: Editora Universidade de Brasília, 2010.

ISER, W. O fictício e o imaginário: perspectivas de uma antropologia literária. Trad. Johannes Kretschmer. 2.ed. Rio de Janeiro: EdUERJ, 2013.

MASSEY, D. O sentido global do Lugar. Trad. Pedro Maia Soares. Oxford: Polity, 1994.

MEC. Coletâneas: poemas - Olimpíada de Língua Portuguesa (Escrevendo o futuro). Brasil, 2014.

MIGNOLO, W. D. Histórias locais/projetos globais. Belo Horizonte: Editora UFMG, 2003.

PETIT, M. Os jovens e a leitura: uma nova perspectiva. Tradução Olga de Souza. São Paulo: Editor 34, 2008.

A arte de ler ou como resistir à diversidade. São Paulo: Editora 34, 2009.

Leituras: do espaço íntimo ao espaço público. Tradução Olga de Souza. São Paulo: Editor 34, 2013.

WALTY, I. L. C. Espaço e espaços. Cadernos de Linguística e Literatura, $\mathrm{n}^{\circ}$ 14. Belo Horizonte: UFMG, 1985, p. 83 a 105. 